\title{
Tratamento focal e perifocal contra Aëdes aegypti
}

* Organizaçăo Panamericana de Saúde, Av. Pedro II, 278 , 20941 Rio de Janeiro.

* Escola Nacional de Saúde Pública, 21041 Rio de Ja. neiro.

\author{
Milton Moura Lima* \\ Mario B. Aragão:
}

Em quatro bairros da cidade do Rio de Janeiro, foram feitos ensaios de tratamento focal com abate granulado a l ppm e perifocal com pó molhável de Sumition a 2,5\%. Esses tra tamentos foram feitos tanto isoladamente quanto em conjunto e, tam bém, associados à aplicação de inseticida a ultrabaixo volume. Os indices prediais, levantados um mês depois de terminado o trabalho, mostraram que o tra tamento focal dispensa qualquer medida auxiliar. $O$ tratamen to perifocal mostrou-se inócuo e incapaz de impedir o aparecimento de lavas de Aëdes aegypti e de outros insetos, em pneus pintados, na face externa, com Sumition e com Malation

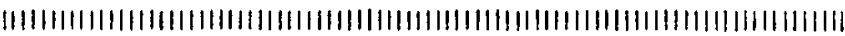

\section{INTRODUÇÃO}

O tratamento dos depósitos. onde se cria o $A \ddot{e} d e s$ aegypti é o mais tradicional. e sua história está relatada em Franco (1969). Em 1901. Emilio Ribas recomendava o uso de querosene de mistura com alcatrão. nos depósitos que não pudessem ser eliminados. Com a mesma finalidade. Oswaldo Cruz usou querosene. creolina e óleo de eucalip to. Clementino Fraga, a petrolagem. e o Serviço Nacional de Febre Amarela. mistura de óleo diesel e fuel. ${ }^{2}$

Na erradicação do $A$. aeglpti do Nordeste brasileiro. quando já existia o DDT. o Dr. Otavio Pinto Severo usou a aplicação desse inseticida nas partes interna externa dos depósitos. o que chamou de tratamento perifical ou preferencial, mét odo que, na realidade. é uma associação do tra. tamento focal com o perifocal. e que deu origem a essa última técnica. O apareciem tno da resistencia ao DDT inutilizou o método. mas. o desenvolvimento de formulações de inseticidas fosforados de liberação lenta possibilitou uma al. ternativa.

A formulaçăo do inseticida temefós (Abate) granula. do, capaz de liberar apenas $0.03 \mathrm{ppm}$ de ingrediente ativo na água e persistir durante trés meses (Agricultural Research Division, s/d), proporcionou uma solução ideal para o tratamento dos depósitos de água potável. Ainda mais que esse 
inseticida é de baixíssima toxicidade para mamíferos, menor que a do sal de cozinha. Apesar da solubilidade dada pelo fabricante do produto $(0,03 \mathrm{ppm})$ não ter sido constatada, na prática, a sua segurança continua aceitável. Trabalhos feitos em Porto Rico e nas llhas Virgens (Brooks et al., 1967; Laws et al., 1968) colocando Abate granulado em tambores de armazenamento de água na dose de $1 \mathrm{ppm}$, do volume do depósito, mostraram que a concentração do produto pode atingir $0,78 \mathrm{ppm}$, mantendo uma média em torno de $0,50 \mathrm{ppm}$. Entretanto, nesses dois trabalhos não foi constatada, entre as pessoas que consumiram essa água, nenhuma anormalidade atribuível ao inseticida, nem queda da atividade da colinesterase. Todavia, como o Abate é caro, passou-se a utilizar outro produto, também fosforado, na parte externa dos depósitos.

O que está acima relatado, sobre os êxtos obtidos no tratamento focal com derivados de petróleo e, também, o fato da elevada irritabilidade do DDT, para os mosquitos, não ser observada com os inseticidas fosforados, sugere que se questione a utilidade do tratamento perifocal feito com esses inseticidas.

\section{MATERIAL E MÉTODOS}

A partir de 1984, vem sendo realizada, no Rio de Janeiro, uma série de pesquisas visando apurar a eficiência relativa das diversas técnicas u tilizadas no controle do $A$. aegypti. as quais têm sido aplicadas tanto isoladas quanto combinadas.

Os bairros trabalhados pertencem à zona norte da cidade e têm as seguintes características:

Cascadura - bairro residencial. predominantemente plano. com uns poucos edifícios baixos;

Benfica - área acidentada, com vilas e ruas estreitas e poucos edifícios:

Rio Comprido - bairro situado nas encostas do maciço da Tijuca, onde predominam casas:

Jacarepaguá - a parte desse bairro que foi trabalhada é relativamete plana, e nela predominam casas e conjuntos de edifícios. os chamados condomínios.

Todos esses bairros são habitados por classe média. sendo que, em Jacarepaguá. o nivel econômico é mais ele. vado.

A aplicação de inseticida a ultrabaixo volume (UBV) obje to de outros artigos e. por isso. não será aqui. descrita.

O tratamento focal foi feito de acordo com a norma adotada pela Superintendencia de Campanhas de Saúde 
Pública (SUCAM) e consiste na adição de Abate granulado a $1 \%$, na dose de 1 ppm de ingrediente ativo, calculada de acordo com o volume do depósito, sem levar em conta a quantidade de água existente, no momento da aplicação.

O tratamento perifocal foi feito pulverizando a parte externa do depósito com pó molhável de Sumition a $40 \%$, diluido a $2,5 \%$.

Com a intenção de testar, mais rigorosamente, a eficiência do tratamento perifocal, foram colocados em algumas casas, onde haviam focos de $A$, aegypti, pneus pintados por fora, com suspensão de Sumition e de Malation, ambas a $2,5 \%$. Na calda utilizada na pintura de metade desses pneus, foi adicionado $0.1 \%$ do espalhante adesivo Extravon.

\section{RESULTADOS E COMENTÁRIOS}

Na tabela 1. os dados referem-se ao indice predial, isto é. número de prédios com depósitos, contendo larvas de A. aegypti em 100 prédios inspecionados. Os índices foram levantados antes e um mès depois da aplicação das diversas técnicas.

O fato do indice predial ter baixado. significativamente, em duas áreas-testemunha é de observação corrente. Durante a inspeção do guarda, as pessoas ticam conhecendo as larvas dos mosquitos e passam a trocar a água dos depósitos ou a eliminá-los, quando voltam a ver essas larvas. $\mathrm{Na}$ tabela 1, vê-se que na área onde só foi aplicado o tratamen. to perifocal. a queda da positividade foi semelhante à observada em duas áreas-testemunha. o que pode. também. ser atribuído à ação da própria população.

A inutilidade do tratamento perifocal ficou patente com o encontro de formas jovens de mosquitos e de quironomídeos, em alguns pneus que tinham a parte externa pintada com inseticida (pó molhável a 2.5\%). Em seis semanas de observação, foram encontradas larvas de $A$. aegypti em pneus que receberam os seguintes tratamentos: Sumithion com espalhante adesivo, 1 pneu na 4 a e 2 na 6 a semana; Malathion puro, 2 pneus na 6 a semana; Malathion com espathante adesivo, 2 pneus na 6 a semana. Além disso. foram encontradas em um pneu pintado com Sumithion puro e outro com Malathion puro, larvas de Aëdes sp. Também, em dois pneus tratados com Sumithion mais espalhante adesivo, apareceram larvas de quironomideos. 
ARTIGO

TABELA 1

Resultados de tratamento contra Aëdes aegyp ti feitos em diversos hairros do Rio de Janeiro, expressos em indices prediais levan tados antes e um mès depois de conchuido o tratamento.

\begin{tabular}{|c|c|c|c|c|c|c|}
\hline $\begin{array}{l}\text { Bairro, data do } \\
\text { início e NO de } \\
\text { prédios }\end{array}$ & $\begin{array}{l}\text { Tratamento } \\
\text { perifocal }\end{array}$ & Testemunha & $\begin{array}{l}\text { Tratamento } \\
\text { focal }\end{array}$ & $\begin{array}{l}\text { Tratamento } \\
\text { focal e perifocal }\end{array}$ & $\begin{array}{l}\text { Tratamento } \\
\text { focal e UBV }\end{array}$ & $\begin{array}{l}\text { Tratamento focal, } \\
\text { perifocal e UBV }\end{array}$ \\
\hline $\begin{array}{l}\text { Benfica } \\
\text { II } / 84, \text { Prédjos } \\
\text { Ind. antes } \\
\text { Ind. depois }\end{array}$ & & $\begin{array}{l}679 \\
14,8 \\
14,0\end{array}$ & $\begin{array}{r}615 \\
11,8 \\
0,0\end{array}$ & $\begin{array}{r}785 \\
14,8 \\
0,1\end{array}$ & & \\
\hline $\begin{array}{l}\text { Rio Comprido } \\
\text { VII/ } 84 \text {, Prédios } \\
\text { Ind. antes } \\
\text { Ind. depois }\end{array}$ & & $\begin{array}{r}480 \\
16,9 \\
11,3\end{array}$ & $\begin{array}{r}516 \\
15,1 \\
0,0\end{array}$ & $\begin{array}{r}550 \\
17,3 \\
0,0\end{array}$ & & \\
\hline $\begin{array}{l}\text { Jacarepaguá } \\
\text { XIl } / 84 \text {, Prédios } \\
\text { Ind. antes } \\
\text { Ind. depois }\end{array}$ & $\begin{array}{r}806 \\
7,8 \\
4,2\end{array}$ & $\begin{array}{r}702 \\
7,7 \\
4,0\end{array}$ & $\begin{array}{r}796 \\
11,6 \\
0,5\end{array}$ & $\begin{array}{r}665 \\
7,7 \\
0,8\end{array}$ & & \\
\hline $\begin{array}{l}\text { Cascadura (1) } \\
\text { II } / 84 \text {, Prédios } \\
\text { Ind. antes } \\
\text { Ind. depols }\end{array}$ & & $\begin{array}{l}679 \\
14,8 \\
14,0\end{array}$ & & & $\begin{array}{r}670 \\
15,2 \\
1,1\end{array}$ & $\begin{array}{r}635 \\
10,8 \\
0,8\end{array}$ \\
\hline
\end{tabular}

(1) Os dado da testemunha são da árca de Benfica, que foi trabalhada na mesma ocasião.

Nota - Tratamento focal com Abate granulado na dose de $1 \mathrm{ppm}$. Tratamento perifocal com suspensão de Sumition a $2,5 \%$. LBV - Aplicação de Sumition a $95 \% \mathrm{~cm}$ ultrabaixo volume, com máquina motorizada na velocidade de $10 \mathrm{Km} / \mathrm{h}$ ora e vazāo de $127 \mathrm{ml} / \mathrm{min}$.

O exane da coluna do tratameto focal e das demais, mostra que ele dispensa qualquer medida complementar. Entretanto, o fato dele sozinho ter levado a zero, o índice de duas áreas é pura questão de acaso e não porque, nessas áreas. o tratamento tenha sido mais minucioso, em virtude do guarda não ter que se preocupar com o tratamento perifocal. Também, na áréa onde foi aplicado, além do tratamento focal. o inseticida a ultrabaixo volume, o índice não foi a zero e os guardas não tinham outra tarefa, além de colocar o inseticida nos de pósitos.

A aplicação de inseticidas a ultrabaixo volume, apesar de eficientissima para reduzir a população de mosquitos adultos. não acrescentou nada ao tratamento focal. É que - Abate mantém-se ativo. durante 14 semanas (Brooks et al.. 1966). sendo assim, tanto faz que existam, ou não, mosquitos para fazer postura. O papel das aplicaçōes de inseticida, a ultrabaixo volume, é outro. Como o tratamento focal é lento. caro e depende de mão-de-obra de boa qualidade. não permite ser estendido, rapidamente. a grandes ieas. Já o UBV aplicado por máquinas montadas sobre viaIdcrnos de Saúde Pública, R.J. 2 (3):142-147, abr/jun, 1987 
turas ou por máquinas costais permite que se trate grandes áreas, rapidamente, mantendo a densidade do $A$. aegypti em índices que impossibilitam a transmissão de doenças, com a vantagem de livrar a população do incômodo causado pelos mosquitos e, às vezes, outros insetos.

\section{CONCLUSÕES}

A conclusão mais óbvia dos presentes ensaios é a confirmação do que vinha sendo observado, ao longo da história, do controle do $A$. aegypti. Desde o tempo de Oswaldo Cruz (Falcão, 1978) até o aparecimento do DDT (Franco, 1969), a espécie tinha sido combatida, unicamente, com tratamento focal, principalmente, com derivados do petróleo, complementado com a eliminação dos depósitos inúteis e vedação dos depósitos de água potável. O expurgo das casas, em épocas de epidemia, destinava-se a eliminar mosquitos infectados, onde ocorriam casos de febre amarela e, praticamente, não tinham nenhuma influênica no controle da espécie.

A aplicação de inseticida a ultrabaixo volume, apesar de altamente eficiente, contra mosquitos adultos, não foi capaz de melhorar a eficacia do tratamento focal.

O tratamento perifocal, com os inseticidas fosforados Sumition e Malation, é destituído de qualquer ação impedidora da postura e da posterior eclosão das larvas. Isso ficou claro com o aparecimento de formas juvens de mosquitos e de outros insetos, em pneus que tinham a face externa recoberta tanto com Sumition quanto com Malation.

\section{AGRADLCIMENTOS}

Os autores são gratos aos servidoles Henrique Emílio Nunes Sampaio, Eudes de Paula e Silva, Mateus G. Ribeiro e Ivan Teixeira, pela dedicação com que executaram as suas tarefas. Ao Dr. Palagio Parigot de Souza, Diretor Regional da SUCAM. agradecem o apoio que vem dando aos trabalhos de pesquisa

In four districts of the city of Rio de Janeiro focal treatment essays with granulated Abate at l ppm and perifocal treatment essays with wettable powder of Sumithion at 2,5\% were performed. These were made either alone or in combination as well as associated to insecticides 
applied at ultra low volume. The premise indices ob tained one month after the treatments indicates that the focal treatment alone is effective, no other addicional methods being necessary. The perifocal treatment is not effective and did not prevent the development of Aedes aegypti larvae and other insects in tires which had their external surface painted with Sumithion and Malathion.

\section{REFERENNCIAS BIBLIOGRÁFICAS}

1. AGRICULTURAL RESEARCH DIVISION Abate larvicide. Princeton, New Jersey, American Cyanamid Company, $\mathrm{s} / \mathrm{d}$.

2. BROOKS, G.D., SHOOF, H.F. \& SMITH, E.A. Evaluation of five formulations of Abatc against Aedes aegypti, Savannah, Georgia, 1965. Mosq. News, 26:580-2, 1966.

3. BOOKS, G.D., SMITH, E. A. \& MILES, J.W. Accumulative effects of repeated Abate granular treatments in water storage drums. Mosq. New's., 27:164-71, 1967.

4. LAWS, E.R. ct al. Ficld study of the safety of Abate for treating potable water and observations on the effectiveness of a control programme involving both Abate and Malathion. Bull. Wld Hith Org., 38:439.45, 1968.

5. FALCÃO, E.C., Ed. Oswaldo Cruz monumenta história Tomo VI Os serviços de saúde pública no Brasil (1808-1907) L`boço histórico. São Paulo, 1978.

6. FRANCO, O. História da febre-amarela no Brasil. Rio de Janciro, Ministério da Saúde, 1969. 